\title{
The Lasting Effect of The Self-Efficacy Promoting Moderate Drinking Program Applied to Female College Students Addicted to Drinking
}

\author{
Gyung Park \\ Dept. of Nursing, Chodang University, Muangun Muanep, Muanro 380, \\ Jeollanamdo, Repulic of Korea \\ gypark@cdu.ac.kr
}

\begin{abstract}
The purpose of this study was to certify the lasting effect of the Self-Efficacy Promoting Moderate Drinking Program on female college students addicted to drinking. This study was based on nonequivalent control group non synchronized design. For data collection was August 2013 - October 2014. This study used the measurement tools were made by the Adolescent committee for the Drinking Related Knowledge, and the Drinking Refusal Selfefficacy made by Aas et al, Korean version by Cho. For the Optimistic Drinking Outcome Expectancy measurement, the study used a tool by Annis, Korean version by Kim. The Problematic Drinking Behavior measured by Shin's measurement tool. To analyze the distinction of dependent variables after the program and follow up after 1 month and 1 year on both groups were used t-test and ANCOVA. The result of this study demonstrated that the effect of the Self-efficacy Promoting Moderate alcohol program lasted at least 1 month after intervention, but it was no longer lasted the effect of the all dependent variables at 1 year. The result demonstrated that it was necessary to check the effect through a repetitive study and longitudinal study of this Moderate Drinking Program to mediate the point in time for intervention to maintain a lasting effect of education.
\end{abstract}

Keywords: Lasting effect, Self-Efficacy, Promoting, Drinking program, Female, College students, Addicted to drinking

\section{Introduction}

In Korea, drinking rate of adult women was $67.2 \%$ in 2014 , especially women who are aged 19-29 confirmed the highest percentage at $86.2 \%$ by statistics on national health and nutrition [1]. Among female college students addicted to drinking $52.8 \%$ were problematic drinkers with an Audit K score of 8 or more [2]. It was even higher rate than among female college students addicted to drinking in the US (20.5\%) [3] The drinking rate of female college students in Korea is so severe. However, $90.5 \%$ of female college students haven't had education about moderate drinking, a large number of female college students, that is, $90.1 \%$ suggested such education is necessary [4]. As reviewed in advance studies in our country, some studies detected that drinking prevention program was applied targeting college students addicted to drinking [5][6][7], but it was rare to find the lasting effect of intervention program in Korea. On the Contrary, for foreign studies certified the lasting effect of a intervention program targeting college students addicted to problematic or heavy drinking,

Article history:

Received (July 02, 2016), Review Result (August 08, 2016), Accepted (September 11, 2016) 
there were a large number of studies to which a brief motivated intervention program [8][9]. The period for which the lasting effect of drinking prevention programs could be certified was various from 1 week to over 1 year. Considering the period of the intervention effect appeared in these advance studies, it could be seen that the point in time for intervention to maintain the changes in drinking behavior was important.

As such, this study implemented to provide the data to determine the point in time for effective intervention of a moderate drinking program with self-efficacy resources on female college students addicted to drinking.

\section{Conceptual framework of the study}

The framework of this study was Bandura's self-efficacy theory. Self-efficacy resources are consist of enactive mastery experience, vicarious experience, verbal persuasion and emotional arousal. This study used the enactive mastery experience, vicarious experience and verbal persuasion among these self-efficacy resources [10].

The conceptual framework of the study is as follows [Figure 1][11].

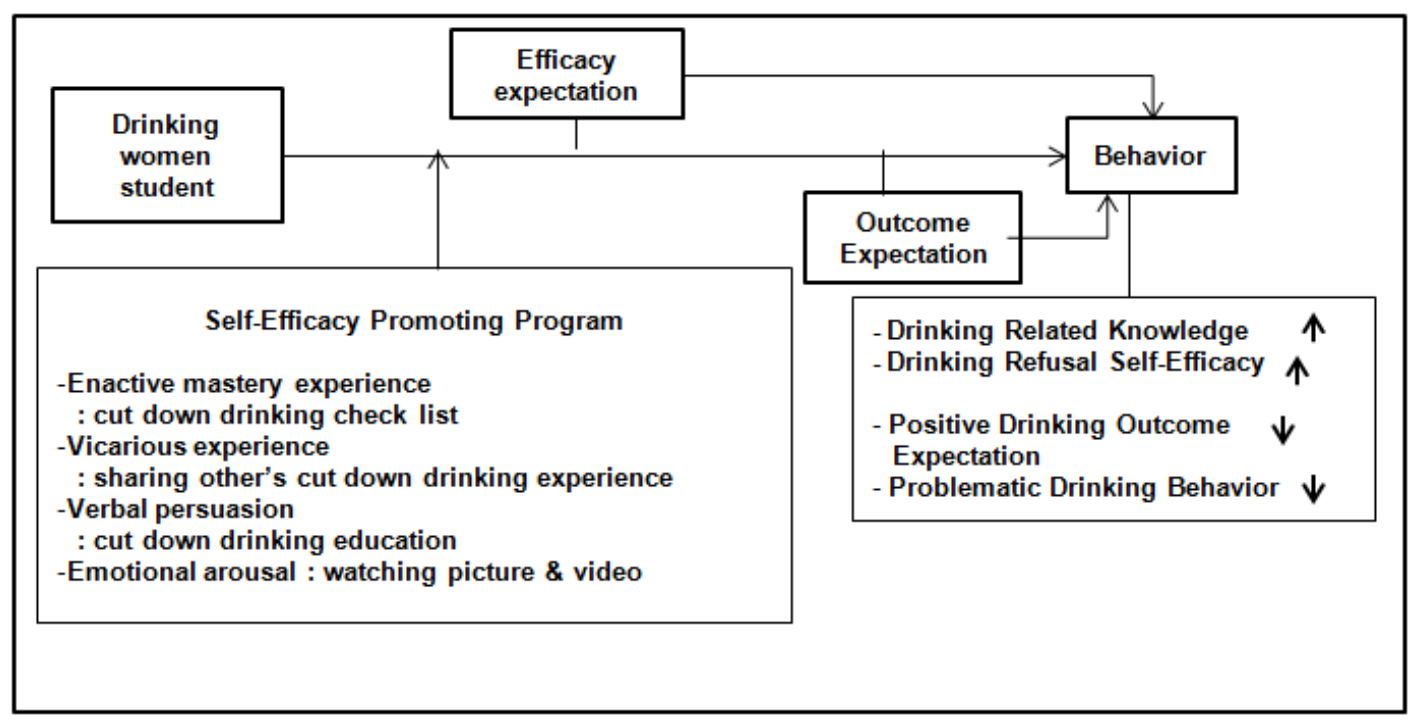

Figure 1. Conceptual framework of the study

\section{Research method}

\subsection{Research design}

This study was a nonequivalent control group non-synchronized design and implemented to certify the effect of a self-efficacy promoting moderate drinking program on female college students addicted to drinking.

\subsection{Participants}

Participants were 48 female college sophomores students addicted to drinking with an Audit score of 8 or more that's WHO's problematic drinking standards were measured who attended $\mathrm{C}$ university in $\mathrm{G}$ metropolitan city and $\mathrm{MC}$ university in $\mathrm{M}$ city of $\mathrm{J}$ Province. 


\subsection{Measurement tools}

To test the effect the Drinking-Related Knowledge, used measurement tool made by the National Youth Commission [12] and the School Education Program [13]. To test the effect the Drinking Refusal Self-Efficacy, used measurement tool modified by Cho [15] made by Aas et al. [14] was used. For the Drinking Outcome Expectancy, using 23 positive the Drinking Outcome Expectancy 41 questions translated by Kim [16] made Annis [17]. And to measure the Problematic Drinking Behavior, used 20 questions developed by Shin [18]. The Self-Efficacy Promoting Moderate Drinking Program is a program that was made by the researcher based on a moderate drinking program in need of 8 periods developed by Do [19] and a drinking prevention program of the Commission on Youth Protection [12] using the intervention of enactive mastery experience, vicarious experience and verbal persuasion, which are the Self-Efficacy resources of Bandura [10]. This program applied to the experimental group once a week with 60 minutes for 8 weeks, total in 8 sessions. This program was confined through consultation with 2 professors in the nursing and 2 professional counseling nurses in Alcohol Counseling Center at two places.

\subsection{Collection and analysis of data}

The data collection was from August 2013 to October 2014. Data Collection time were through four times, pretest, shortly after intervention, 1 month, 1 year. The collected data were analyzed using the SPSS WIN 20.0 program. To certify the normal distribution used Kolmogorov-Smirnov test. To certify the homogeneity of general characteristics on experimental group and control group, used $\chi^{2}$-test and t-test. To certify the distinctions dependent variables and after 1 month, after 1 year between the experimental group and the control group, used t-test and ANCOVA.

\section{Results}

The results of this study are as follows.

(1). The homogeneity for general characteristics of two groups certified that there were no significant distinctions, so, two groups were homogeneity. There were no significant distinctions looked for between two groups pre-experiment, shown the homogeneity in the Drinking-Related Knowledge ( $\mathrm{t}=1.07, p=.290)$, the Drinking Refusal Self-Efficacy $(\mathrm{t}=0.42$, $p=.680)$, the Drinking Outcome Expectancy $(\mathrm{t}=0.40, p=.688)$, and the Problematic Drinking Behavior $(\mathrm{t}=-0.10, p=.918)$

(2). Shortly after the program was applied, there were significant distinctions detected through covariance analysis between two groups in the Drinking-Related Knowledge $(t=6.15$, $p<.001)$, the Drinking Outcome Expectancy $(\mathrm{t}=-2.89, p=.006)$, and the Problematic Drinking Behavior ( $\mathrm{F}=5.57, p=.003$ ), so the effect of the program was able to be affirmed. But in the area of the Drinking Refusal Self-Efficacy $(\mathrm{t}=0.90, p=.376)$, there were no significant distinctions between the two groups [Table 1].

(3). Follow-up 1 month: There were significant distinctions between two groups in the Drinking-Related Knowledge ( $\mathrm{t}=9.69, p<.001)$, the Drinking Refusal Self-Efficacy $(\mathrm{t}=8.16$, $p<.001)$, the Drinking Outcome Expectancy $(\mathrm{t}=-3.85, p<.001)$ and the Problematic Drinking Behavior ( $\mathrm{t}=-4.36, p<.001)$ [Table 2].

(4). Follow-up 1 year: There were significant distinctions between two groups in the Drinking-Related Knowledge $(\mathrm{t}=4.36, p<.001)$ and the Drinking Refusal Self-Efficacy 
$(\mathrm{t}=2.92, p<.001)$, but there were no significant distinctions between two groups in the Drinking Outcome Expectancy $(\mathrm{t}=-9.25 p=.362)$ and the Problematic Drinking Behavior $(\mathrm{t}=-$ 1.66, $p=.108$ ) [Table 2].

Table 1. Homogeneity test of dependent variables between two groups at pretest

\begin{tabular}{|c|c|c|c|c|}
\hline \multirow{2}{*}{ Variables } & Exp.(n=22) & Cont.(n=24) & \multirow{2}{*}{$\mathrm{t}$} & \\
\cline { 2 - 4 } $\begin{array}{c}\text { Drinking } \\
\text { related knowledge }\end{array}$ & $6.3 \pm 0.89$ & $6.0 \pm 0.86$ & 1.07 & .290 \\
\hline $\begin{array}{c}\text { Drinking } \\
\text { Refusal } \\
\text { Self-Efficacy }\end{array}$ & $17.0 \pm 3.15$ & $16.6 \pm 3.61$ & 0.42 & .680 \\
\hline $\begin{array}{c}\text { Alcohol } \\
\text { Outcome Expectancy }\end{array}$ & $31.2 \pm 7.82$ & $30.2 \pm 8.47$ & 0.40 & .688 \\
\hline $\begin{array}{c}\text { Problematic } \\
\text { Drinking behavior }\end{array}$ & $11.2 \pm 5.13$ & $11.4 \pm 4.53$ & -0.10 & .918 \\
\hline
\end{tabular}

Table 2. Comparison of dependent variables between two groups at post-test, after 1 month \& 1 year

\begin{tabular}{|c|c|c|c|c|c|c|c|c|c|c|}
\hline \multirow{3}{*}{ Variables } & \multicolumn{2}{|c|}{ Post-test } & \multirow{3}{*}{$\mathrm{t}(p)$} & \multirow{3}{*}{$\mathrm{F}(p)$} & \multicolumn{2}{|c|}{ After 1 Month } & \multirow{3}{*}{$\mathrm{t}(p)$} & \multicolumn{2}{|c|}{ After 1 year } & \multirow{3}{*}{$\mathrm{t}(p)$} \\
\hline & $\begin{array}{c}\text { Exp. } \\
(\mathrm{n}=22 \\
)\end{array}$ & $\begin{array}{l}\text { Cont. } \\
(n=24)\end{array}$ & & & $\begin{array}{c}\text { Exp. } \\
(\mathrm{n}=22 \\
)\end{array}$ & $\begin{array}{l}\text { Cont. } \\
(n=24)\end{array}$ & & $\begin{array}{c}\text { Exp. } \\
(n=21)\end{array}$ & $\begin{array}{l}\text { Cont. } \\
(\mathrm{n}=24)\end{array}$ & \\
\hline & $\begin{array}{c}\mathrm{M} \pm \mathrm{S} \\
\mathrm{D}\end{array}$ & $\mathrm{M} \pm \mathrm{SD}$ & & & $\begin{array}{c}\mathrm{M} \pm \mathrm{S} \\
\mathrm{D}\end{array}$ & $\mathrm{M} \pm \mathrm{SD}$ & & $\mathrm{M} \pm \mathrm{SD}$ & $\mathrm{M} \pm \mathrm{SD}$ & \\
\hline $\begin{array}{c}\text { Drinking } \\
\text { Related } \\
\text { Knowledge }\end{array}$ & $\begin{array}{c}9.3 \pm 0 \\
.88\end{array}$ & $\begin{array}{c}7.3 \pm 1.2 \\
3\end{array}$ & $\begin{array}{c}6.15 \\
(<.00 \\
1)\end{array}$ & $\begin{array}{c}14.33 \\
(<.001 \\
\quad)\end{array}$ & $\begin{array}{c}8.7 \pm .8 \\
4\end{array}$ & $6.5 \pm .65$ & $\begin{array}{c}9.69 \\
(<.001)\end{array}$ & $\begin{array}{c}8.6 \pm 0.8 \\
1\end{array}$ & $\begin{array}{c}7.50 \pm 0 \\
.83\end{array}$ & $\begin{array}{c}4.36 \\
(<.001 \\
\quad)\end{array}$ \\
\hline $\begin{array}{c}\text { Drinking } \\
\text { Refusal } \\
\text { Self-fficacy }\end{array}$ & $\begin{array}{c}20.7 \pm \\
3.70\end{array}$ & $\begin{array}{c}19.3 \pm 6 \\
55\end{array}$ & $\begin{array}{c}0.90 \\
(.376)\end{array}$ & $\begin{array}{c}0.64 \\
(.593)\end{array}$ & $\begin{array}{c}24.0 \pm \\
2.71\end{array}$ & $\begin{array}{c}16.9 \pm 3 \\
15\end{array}$ & $\begin{array}{c}8.16 \\
(<.001)\end{array}$ & $\begin{array}{c}23.7 \pm 4 \\
20\end{array}$ & $\begin{array}{c}20.0 \pm 4 \\
.69\end{array}$ & $\begin{array}{c}2.92 \\
(.006)\end{array}$ \\
\hline $\begin{array}{c}\text { Alcohol } \\
\text { Outcome } \\
\text { Expectancy }\end{array}$ & $\begin{array}{c}23.6 \pm \\
7.91\end{array}$ & $\begin{array}{c}30.5 \pm 8 \\
37\end{array}$ & $\begin{array}{l}-2.89 \\
(.006)\end{array}$ & $\begin{array}{c}18.23 \\
(<.001 \\
\quad)\end{array}$ & $\begin{array}{c}21.0 \pm \\
7.47\end{array}$ & $\begin{array}{c}30.2 \pm 8 \\
46\end{array}$ & $\begin{array}{c}-3.85 \\
(<.001)\end{array}$ & $\begin{array}{c}27.4 \pm 11 \\
.9\end{array}$ & $\begin{array}{c}30.2 \pm 7 \\
.97\end{array}$ & $\begin{array}{l}-9.25 \\
(.362)\end{array}$ \\
\hline $\begin{array}{c}\text { Problematic } \\
\text { Drinking } \\
\text { Behavior }\end{array}$ & $\begin{array}{c}8.6 \pm 6 \\
.43\end{array}$ & $\begin{array}{c}10.4 \pm 4 \\
14\end{array}$ & $\begin{array}{l}-0.10 \\
(.795)\end{array}$ & $\begin{array}{c}5.57 \\
(.003)\end{array}$ & $\begin{array}{c}4.95 \pm \\
5.26\end{array}$ & $\begin{array}{c}11.4 \pm 4 \\
53\end{array}$ & $\begin{array}{c}-4.36 \\
(<.001)\end{array}$ & $\begin{array}{c}7.29 \pm 7 \\
63\end{array}$ & $\begin{array}{c}10.4 \pm 4 \\
.14\end{array}$ & $\begin{array}{l}-1.66 \\
(.108)\end{array}$ \\
\hline
\end{tabular}

\section{Conclusion}

This study is a nonequivalent control group non-synchronized design. This study 
implemented to affirm the lasting effects of the Self-Efficacy Moderate Drinking Program by applied on drinking female college students. Then this study affirmed the changes in the Drinking-Related Knowledge, the Drinking Refusal Self-Efficacy, the Drinking Outcome Expectancy and the Problematic Drinking Behavior at shortly after, at 1 month, at 1 year after intervention to experiment group. It could be affirmed that this was an effective drinking prevention education program applicable to drinking female college students. As a result, the lasting effect of education in this program was detected that there were no significant distinctions in the Drinking Refusal Self-Efficacy shortly after intervention, but it was revealed that there were significant distinctions in the Drinking Refusal Self-Efficacy at 1 month and at 1 year after intervention, and the effect of education lasted in all dependent variables, that is, the Drinking-Related Knowledge, the Drinking Refusal Self-Efficacy, the Drinking Outcome Expectancy and the Problematic Drinking Behavior at 1 month. But there were no significant distinctions in the Drinking Outcome Expectancy, the Problematic Drinking Behavior at 1 year after intervention, so it meant that the effect of Moderate Drinking Program was partly kept. Considering in advance studies, we could see that most important thing is intervention time to keep the effect of education. So it was necessary to check the effect through a repetitive study of this program and that it was also necessary to adjust the time for intervention in order to achieve the lasting effect of education to drinking female college students.

\section{References}

[1] http://kosis.kr. Korean Statistical Information Service, (2016)

[2] E. Y. Do, Y. H. Kim, and J. H. Kim, "Comparison of problem drinking and alcohol expectancy among female college students," Workers and Housewives, Journal of Korean Alcohol Science, vol.10, no.1, pp.93106, (2009)

[3] S. G. Chun, A. R. Shon, C. G. Song, and J. E. Park, "Comparison of alcohol use among Korean and U.S. college students," Journal of Korean Alcohol Science, vol.7, no.1, pp.1-11, (2006)

[4] J. H. Lee, "Fact-finding on drinking culture of female college student (whose majors are Food \& Nutrition or Nursing) in Gwangju," Unpublished master dissertation, Chonnam National University, Gwangju, Korea, (2013)

[5] S. S. Chun, "Analysis of college student binge drinking and alcohol-related problems. J of Korean alcohol science," vol.23, no.2, pp.221-233, (2002)

[6] H. I. Lee and C. N. Son, "The effects of motivational program on alcohol expectancy, abstinence selfefficacy," and Problematic Drinking in College Students, The Korean journal of stress research, vol.17, no.3, pp.237-245, (2009)

[7] G. G. Kim, J. Je Gal, M. S. Park, and J. G. Lee, "Development and efficacy evaluation of a web-based prevention program of alcohol-related problem for university students," Korean Journal of Health Education and Promotion, vol.28, no.5, pp.131-143, (2011)

[8] C. E. Werch, D. M. Owen, J. M. Carlson, C. C. DiClemente, P. Edgemon, and M. Moore, "One-year followup results of the STARS for families alcohol prevention program," Health Education Research, vol.18, no.1, pp.74-87, (2003)

[9] K. B. Carey, M. P. Carey, S. A. Maisto, and J. M. Henson, "Brief motivational interventions for heavy college drinkers: A randomized controlled trial,” Consulting Clinical Psychology, vol.74, no.5, pp.943-954, (2006)

[10] Bandura and E. A, "Self-efficacy: toward a unifying theory of behavioral change. Psychological review," vol.84, no.2, pp.191-215, (1977) 
[11] G. Park, "Effect of Self-efficacy promoting reducing alcohol program on drinking related knowledge, drinking outcome expectancy and problematic drinking behavior of women college students," Unpublished doctoral dissertation, Chonnam National University, Gwangju, Korea, (2014)

[12] The Commission on Youth Protection, 12 forums for the drinking prevention of youth, Seoul: the Commission on Youth Protection under the Prime Minister, (2002)

[13] The Commission on Youth Protection, the results of 2005 Comprehensive Status Survey on Hazardous Environment for Youth, Seoul: The Commission on Youth Protection under the Prime Minister, (2006)

[14] Aas, Klepp, Laberg, and Aaro, "Predicting adolescents' intention to drink alcohol: outcome expectancy and self-efficacy," Journal of Study on Alcohol, vol.51, pp.293-299, (1995) DOI:10.1016/0376-8716(95)01121$\mathrm{E}$

[15] H. Cho, "Developing a predictive model for alcohol consumption behavior among Korean university students. Unpublished doctoral dissertation," Yonsei National University, Seoul, Korea, (2000)

[16] H. M. Annis, "Outcome expectancies questionnaire," In Letteri, D, j., Nelson, J, e., \& Sayers, M. A.(eds.), Alcoholism treatment assessment research instruments, MD: NIAAA, pp.36-39, (1985)

[17] S. J. Kim, "Modeling relapse of Alcoholism: Male alcoholic in-patients of psychiatric ward," Ph.D. dissertation, Seoul National University, Seoul, Korea, (1996)

[18] H. W. Shin, "The effects of personality, drinking motivation on drinking problems," Ph.D. dissertation, Korea University, Seoul, Korea, (1998)

[19] E. Y. Do, "Effects of the drinking-reduction program adopting transtheoretical and leisure models on problem drinking behavior and cognition. Ph.D. dissertation," Kyungpook National University, Kyungpook, Korea, (2004)

\section{Authors}

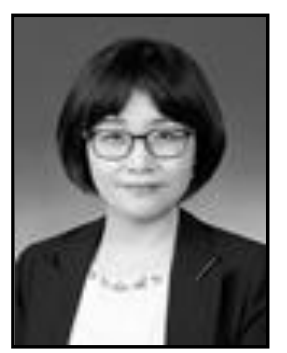

\section{Gyung Park}

Doctor of Nurse science, Chonnam National University Graduate School, Gwangju, Korea.

Professor of Chodang University. 